\title{
Pharmacological Control of Estrus in Tropical Cattle, an Economical Assessment of Different Synchronization Protocols
}

\author{
_Economics of Estrus Control in Tropical Cows
}

\author{
Juan J. Molina ${ }^{1}$, Iván Molina ${ }^{2}$, Alejandro Jiménez ${ }^{3}$, Carlos S. Galina ${ }^{3}$, Juan J. Romero ${ }^{4,5 *}$ \\ ${ }^{1}$ Asesor Laboratorios Intervet Schering Plough, Bogotá, Colombia \\ ${ }^{2}$ Director Técnico Agropecuaria Las Tinajas S. A., Bogotá, Colombia \\ ${ }^{3}$ Departamento de Reproducción, Facultad de Medicina Veterinaria y Zootecnia, Universidad Nacional Autónoma de México, \\ Mexico City, México \\ ${ }^{4}$ Programa de Investigación en Medicina Poblacional, Escuela de Medicina Veterinaria, Universidad Nacional, Heredia, Costa Rica \\ ${ }^{5}$ Campus Benjamín Núñez, Heredia, Costa Rica \\ Email: *jromero@medvet.una.ac.cr
}

Received July 12, 2012; revised August 3, 2012; accepted August 9, 2012

\begin{abstract}
To compare the fertility results and to assess the cost-effectiveness of several synchronization protocols applied under the conditions of beef cattle enterprises in Colombia, 1658 multiparous zebu crossbred cows mostly Brahman and Nelore ranging between 2 - 6 parities were used. Five protocols of pharmacological treatments varying in hormones used, dosage and the time of application were tested. All cows were inseminated at $52 \mathrm{~h}$ by appointment. Pregnancy diagnosis was undertaken over $45 \mathrm{~d}$ after insemination by rectal palpation. The total cost per cow and the total cost per gestation, for each protocol, were calculated. Taking a herd of one-hundred cows as baseline for calculations, it was estimated the cost of the total amount of pregnancies possibly obtained in each protocol; then, the excess between the costs of a pregnant cow and the cost of a treated cow was estimated. Additionally, the costs due to cows empty after four services were calculated. A total of 874 pregnancies were registered (52.7\%), with pregnancies per protocol varying between $46.9 \%$ and $66.2 \%(\mathrm{p}<005)$. The cost per treated cow, varied between $\$ 64.08$ and $\$ 97.47$ and the cost per gestation from $\$ 126.01$ to $\$ 177.26$, without association between the cost of the treatment and the pregnancy rate. Protocol A was the best cost-effective with the lowest additional costs, the lowest amount of open days (2107.7 to $2231.7 \mathrm{~d}$ ) and IA straws (average $=134$ ), with an additional costs of $\$ 6940.00$. Synchronization of estrus using pharmacological products seems to have a place in the management of cattle; however, caution should be called upon a careful assessment both from the part of the farm and the professional in charge of the enterprise to avoid using the technique indiscriminatively thus propitiating the use of a method that might not be cost efficient.
\end{abstract}

Keywords: Tropics; Bos Indicus; Cost-Benefit; Estru; Synchronization

\section{Introduction}

The use of Artificial Insemination in the tropics has been hampered by the difficulties in accurate detection of signs of estrus in Zebu type cattle, the most popular crossbred animal in the beef industry of the area. One possible solution to implement the technique is to manipulate pharmacologically the estrous cycle and coupling this procedure with fixed-time artificial insemination (F-TAI) regardless the signs of estrus, so called insemination by appointment. In relation to animals kept at pasture under tropical conditions, the rate for detecting

${ }^{*}$ Corresponding author. animals in estrus does not go beyond $40 \%$ [1,2]. The reasons for this low detection rate is multifactorial mainly related to social behavior in the herd [3], age, breed of the animals and the presence of the male [4,5]. Because of these limitations, the number of protocols to synchronize estrus is abundant $[5,6]$, the same can be noted as to the hour(s) where F-TAI is applied following removal of the treatment $[7,8]$. However, few studies are published whilst comparing protocols under the same conditions and with the same clinicians applying the procedure, particularly under beef cattle enterprises in the tropics.

Interventions in the beef cattle industry have to be cost 
effective and render economic dividends to the producer otherwise they will become an academic exercise. For example Tenhagen et al. [9] showed that synchronization of estrus in dairy cows in the USA was more cost-effective than inseminating animals displaying overt signs of estrus and this was mainly due to more cows that were culled and more open days among cows not culled. However, Hoff-Sousa and Ferrugem-Moraes [10] in beef cattle raised in southern Brazil, showed that whilst the total cost for a pregnancy using natural mating was 5 dollars, this cost increased to 20 dollars if AI was to be applied and 24 if AI was accompanied with an estrous synchronization protocol. Oltenacu et al. [11] in the USA working with dairy cows undertook an economic evaluation of several factors that affect pregnancy. Accurate estrus detection was among the most profitable managerial decisions. Thus, economic calculations will certainly differ according to the type of enterprise and production item to be evaluated.

The objective of the present study is to compare the fertility results and to assess the cost-effectiveness of several protocols applied under the conditions of beef cattle enterprises in Colombia.

\section{Material and Methods}

\subsection{Animals}

A total of 1658 multiparous zebu crossbred cows, mostly Brahman and Nelore, were chosen from 4 farms located in the Department of Antioquia-Medellin, Puerto Berrío, Colombia. The site is located at $125 \mathrm{~m}$ above sea level, at $06^{\circ} 29^{\prime} 40^{\prime \prime}$ latitude north and $74^{\circ} 24^{\prime} 24^{\prime \prime}$ longitude west. Average temperature is around $29^{\circ} \mathrm{C}$ and pluvial precipitation around $2300 \mathrm{~mm}$. Animals ranged from 4 to 12 years old, with 2 to 6 parities. The selection was done by the same two practitioners based on: 1) having at least 40 days since calving when the synchronization procedure was implemented; 2) the body condition score of the cows, including only those with a minimum of 2.5 in a scale 1 to 5; and 3) presence of a corpus luteum, or traces of follicular activity, detected by rectal palpation.

\subsection{Treatments}

Five protocols of pharmacological treatments were observed on field conditions. All used a synthetic progestagen $\left(\right.$ Crestar $^{\circledR}$, Intervet Schering Plough Animal Health) as base at day 0 , with several variations between them like the hormones used, dosage and the time of application (Table 1). Not all protocols were used in each farm because that depended of the willingness of the farmers; however, all of them were applied under the supervision of the same two veterinarians. Moreover, in order to distribute similarly the experimental error, all cows were inseminated by the same veterinarians following the FTAI at $52 \mathrm{~h}$. In farms where two or more protocols were applied, cows were randomly allocated in each treatment.

No experimentation was performed during this study, this was an observational study of the estrus synchronization on field conditions. The approval of the Animal Welfare and Bioethics Committee of the Veterinary School of the National University in Costa Rica was obtained.

\subsubsection{Pregnancy Diagnosis}

In all protocols the pregnancy diagnosis was done over $45 \mathrm{~d}$ after insemination by rectal palpation by the same veterinarians that selected and treated the cows. They have at least ten years of experience in this kind of reproductive procedures.

\subsubsection{Cost Analyses}

To assess the monetary cost of each protocol, it was calculated the cost of the pharmaceutical treatments, adding the costs for the professional labor of the veterinarians. The rate of each hormone was estimated using the current price in Mexico quoted in US dollars as currency. So, the price for each dose of drug was the following: Norgestomet (Crestar ${ }^{\circledR}$ implant) + estradiol valerate (Crestar ${ }^{\circledR}$ injection), \$15.87; equine chorionic gonadotropin (Folligon ${ }^{\circledR}$ ), \$16.27; estradiol benzoate (Me$\operatorname{salin}^{\circledR}$ ), \$4.65; gonadorelin (Fertagyl ${ }^{\circledR}$ ), $\$ 18.30$; cloprostenol (Estrumate ${ }^{\circledR}$ ), \$14.48; estradiol ciprionate, \$9.58. All these products are manufactured by Intervet Schering Plough Animal Health. Additionally, the cost for the professional labor of the veterinarian was estimated in a total of $\$ 20.00$ per cow for the whole treatment. At last, the mean price for the semen was fit on $\$ 10.00$. The total cost for veterinary services during the complete protocol, including all the visits, was estimated on $\$ 20.00$ per cow.

With these data, the total cost per cow (TCPC) for each protocol (TCPP), was calculated. Once the pregnancy rate (PR) of each protocol was obtained, a calculation of the cost of each gestation (TCG) was done as follows: TCG $=$ TCPC/PR .

Taking a herd of one-hundred cows as baseline for calculations, it was estimated the cost of the total amount of pregnancies possibly obtained in each protocol (CTPP) using the formula: CTPP $=(100 * \mathrm{PR}) *$ TCG. Finally, in order to have a relative estimation of the cost of a gestation per protocol, the excess between the cost of a pregnant cow in relation to the cost a treated cow (EPP) was calculated using the formulae EPP $=($ TCG/TCPC $) * 100$.

The estimation of both costs for a treated cow and for a pregnant animal, at $95 \%$ of confidence was carried out using @RISK 5.7 software (Palisade ${ }^{\circledR}$ ), using the mod- 
Table 1. Description of protocols used for heat synchronization in zebu cows on field conditions in the humid tropic of Colombia. The name of the product in bolds indicates the hormone that makes the treatment different.

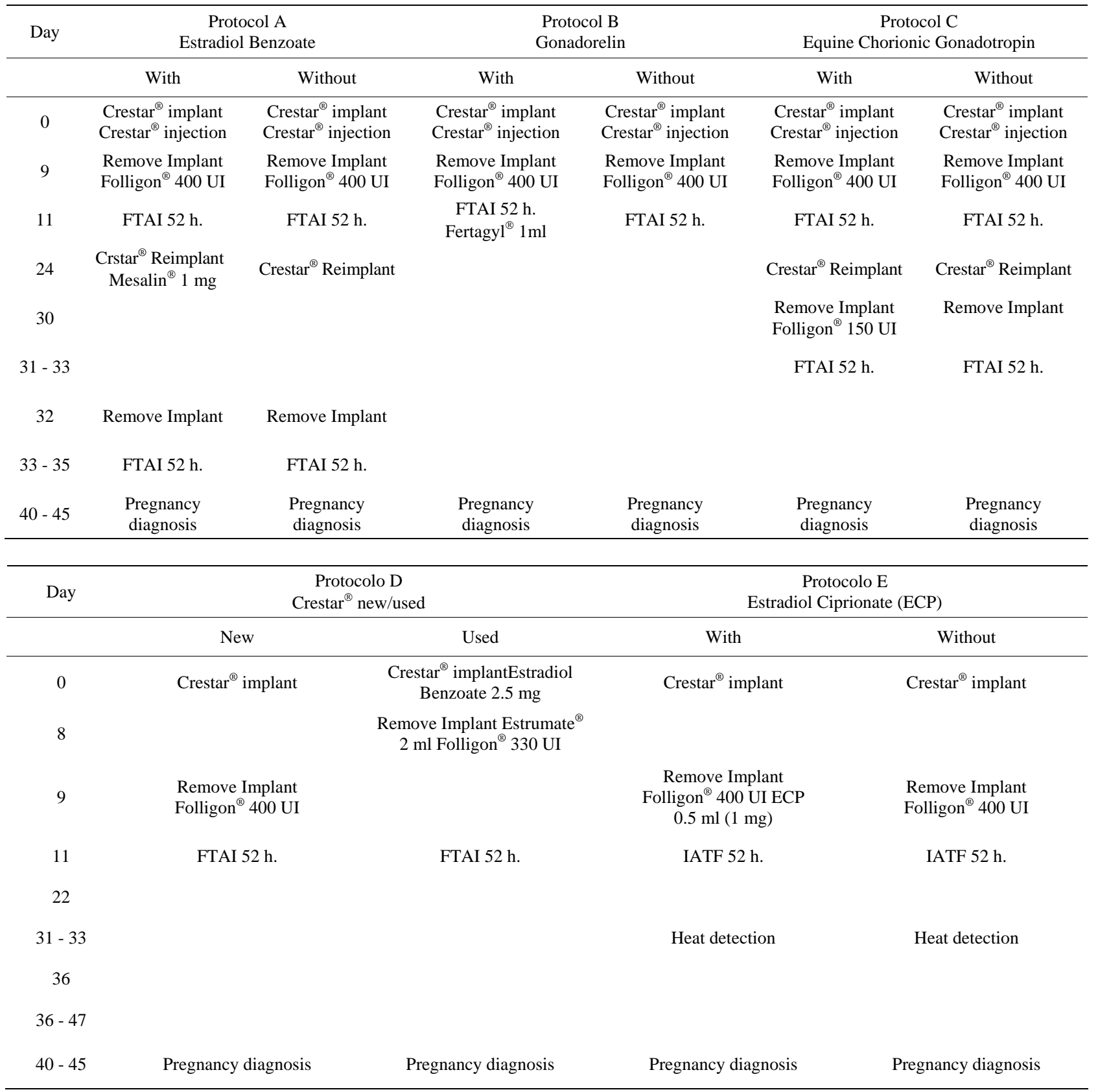

FTAI 52 h = Fixed time artificial insemination, Crestar $^{\circledR}$ : Implant (Norgestomet 3 mg) + Injection (Norgestomet 3 mg, Estradiol Valerate 5 mg), Folligon ${ }^{\circledR}$ eCG (equine Chorionic Gonadotropin), Fertagyl ${ }^{\circledR}:$ GnRH(Gonadotropin Release Hormone), Mesalin ${ }^{\circledR}$ : Estradiol beanzoate.

cost estimation assuming a variation of $\pm 10 \%$ from the base price for each component of the treatment. The variation from demean was obtained after a run with 10,000 iterations. Additionally, an approach of the costs for the owner due to cows empty after four services, for each protocol was estimated by means of a deterministic model carried out in Microsoft Excel. For this purpose, it was assumed a constant pregnancy rate (the observed one in the protocol i.e. fertility at first insemination) for each time of AI and a heat interval of $21 \mathrm{~d}$. This calculation included the total amount of days empty, AI straws projected to use and their associated costs assuming a cost of $\$ 3.00$ US dollars per day empty and a cost of $\$ 10.00$ US dollars per AI straw.

The costs for the remaining days empty and AI straws after four services were not estimated. Cost for management, feed, and others related to the maintenance of the herds was not taken into consideration due to the vari- 
ability in the sample.

\section{Results}

\subsection{Reproductive Efficacy of the Protocols}

A total of 874 pregnancies were registered from the 1658 cows studied (52.7\%). The general percentage of pregnancies per protocol varied between $66.2 \%$ (protocol A) and $46.9 \%$ (protocol D). There were not differences between protocols B, C, D and E, but all of them were different to protocol A (Table 2). When segregating the results per treatment within each protocol, these percentages vary to $66.9 \%$ for protocol A with estradiol benzoate, and $43.7 \%$ for protocol D with the re-used implant of Norgestomet $(\mathrm{p}<0.05)$ (Table 2).

\subsection{Costs per Treated Cow (Gross Cost)}

Regarding the cost per treated cow, in average, protocol D was the cheaper whilst protocol $\mathrm{C}$ was the most expensive. Even within each protocol, the total cost varied between 64.08 US dollars for protocols B and D; specifically without Gonadorelin and with the new Crestar ${ }^{\circledR}$, respectively, while it was $\$ 97.47$ for protocol C when using eCG (Table 3).

\subsection{Costs per Pregnant Cow (Net Cost per Pregnancy)}

When the pregnancy rate was taken into account, the cost for each gestation varied from $\$ 126.01$ in protocol A without estradiol benzoate, to $\$ 177.26$ in protocol C with eCG $(\mathrm{P}<0.05)$. No statistical differences were found in the net cost per pregnancy within each protocol; however, the absolute difference in some protocols was quite important. For instance, in protocol B, there was an absolute difference of $\$ 29.97$ while in protocol D it was $\$ 26.57$ (Table 3). So, at the end, although protocol B without Gonadorelin was the cheaper regarding the gross cost of treatment (\$64.08), it was, the second one with the higher excess cost between treated and pregnant cows (\$121.27). Besides, the protocol D had excess costs of $\$ 99.10$ and $\$ 128.86$ when using new and re-used Cre$\operatorname{star}^{\circledR}$ (Table 3). These results indicate that there is not a direct association between the cost of the treatment and its efficacy measured as pregnancy rate.

Table 2. Percentage of gestations, by protocols used for heat synchronization, in zebu cows on field conditions in the humid tropic of Colombia.

\begin{tabular}{|c|c|c|c|c|c|c|c|}
\hline \multirow{2}{*}{ Protocol } & \multirow{2}{*}{ Treatment } & \multirow{2}{*}{ Total } & \multirow{2}{*}{ Gestations } & \multirow{2}{*}{$\%$} & \multicolumn{2}{|c|}{$95 \%$ CI } & \multirow[t]{2}{*}{ Diff." } \\
\hline & & & & & $\mathrm{IL}$ & SL & \\
\hline A & Total & 394 & 261 & 66.2 & 61.6 & 70.9 & $\mathrm{a}$ \\
\hline \multirow[t]{2}{*}{ Estradiol benzonate } & With & 305 & 204 & 66.9 & 61.6 & 72.2 & \\
\hline & Without & 89 & 57 & 64.0 & 54.1 & 74.0 & 0.70 \\
\hline B & Total & 280 & 131 & 46.8 & 40.9 & 52.6 & $\mathrm{~b}$ \\
\hline \multirow[t]{2}{*}{ Gonadorelin } & With & 145 & 70 & 48.3 & 40.1 & 56.4 & \\
\hline & Without & 135 & 61 & 45.2 & 36.8 & 53.6 & 0.63 \\
\hline $\mathrm{C}$ & Total & 82 & 44 & 53.7 & 43.9 & 64.5 & a,b \\
\hline \multirow[t]{2}{*}{ Equine chorionic gonadotropin } & With & 40 & 22 & 55.0 & 39.6 & 70.4 & \\
\hline & Without & 42 & 22 & 52.4 & 37.3 & 67.5 & 0.82 \\
\hline $\mathrm{D}$ & Total & 601 & 282 & 46.9 & 42.9 & 50.9 & b \\
\hline Implant of norgestomet & New & 301 & 151 & 50.2 & 44.5 & 55.8 & \\
\hline (new/used) & Used & 300 & 131 & 43.7 & 38.1 & 49.3 & 0.12 \\
\hline E & Total & 301 & 156 & 51.8 & 46.2 & 57.5 & b \\
\hline \multirow[t]{2}{*}{ Estradiol ciprionate } & With & 198 & 104 & 52.5 & 45.6 & 59.5 & \\
\hline & Without & 103 & 52 & 50.5 & 40.8 & 60.1 & 0.81 \\
\hline
\end{tabular}

"Different letters indicate difference in the global percentage of gestations between protocols. The numbers indicate the exact P-value of the comparison within each protocol; both calculations at $95 \%$ of confidence. 
Table 3. Costs analyses for each protocol of synchronization used for heat synchronization in zebu cows on field conditions in the humid tropic of Colombia.

\begin{tabular}{|c|c|c|c|c|c|c|c|c|c|c|}
\hline \multirow{3}{*}{ Parameter } & \multicolumn{2}{|c|}{ Protocol A } & \multicolumn{2}{|c|}{ Protocol B } & \multicolumn{2}{|c|}{ Protocol C } & \multicolumn{2}{|c|}{ Protocol D } & \multicolumn{2}{|c|}{ Protocol E } \\
\hline & \multicolumn{2}{|c|}{ Estradiol benzoate } & \multicolumn{2}{|c|}{ Gonadorelin } & \multicolumn{2}{|c|}{ eCG } & \multicolumn{2}{|c|}{ Norgestomet new/used } & \multicolumn{2}{|c|}{ ECP } \\
\hline & With & Without & With & Without & With & Without & New & Used & With & Without \\
\hline$\%$ of gestation & 66.9 & 64.0 & 48.3 & 45.2 & 55 & 52.4 & 50.2 & 43.7 & 52.5 & 50.5 \\
\hline Total cost per treated cow ${ }^{*}$ & 85.33 & 80.59 & 82.70 & 64.08 & 97.47 & 80.62 & 64.12 & 67.39 & 73.94 & 64.21 \\
\hline Cost per gestation ${ }^{\beta}$ & 127.66 & 126.01 & 171.76 & 141.79 & 177.26 & 153.63 & 127.66 & 154.23 & 140.78 & 127.00 \\
\hline $\begin{array}{c}\text { Excess cost pregnant/treated } \\
\text { cow }(\%)^{*}\end{array}$ & 49.61 & 56.36 & 107.69 & 121.27 & 81.86 & 90.56 & 99.10 & 128.86 & 90.40 & 97.79 \\
\hline $\begin{array}{l}\text { Cows pregnant after } 4 \\
\text { services }^{* * *}\end{array}$ & 83 & 82 & 73 & 72 & 77 & 75 & 74 & 71 & 75 & 74 \\
\hline $\begin{array}{c}\text { Total of AI straws until } 4 \\
\text { services }^{* * *}\end{array}$ & 133 & 135 & 151 & 154 & 144 & 147 & 149 & 156 & 147 & 149 \\
\hline $\begin{array}{c}\text { Total of days empty until } 4 \\
\text { services }\end{array}$ & 2107.7 & 2231.7 & 3223.6 & 3409.6 & 2789.6 & 2975.6 & 3099.6 & 3533.5 & 2975.6 & 3099.6 \\
\hline Total cost due to days empty & 6155.8 & 6695.1 & 9615 & 10191.5 & 8368.9 & 8852.5 & 9261.6 & 10470.4 & 8833.9 & 9205.8 \\
\hline $\begin{array}{l}\text { Additional costs due to IA + } \\
\text { days empty }{ }^{* * * * *}\end{array}$ & 6648.3 & 7230.8 & 10384.3 & 11006.9 & 9038.5 & 9560.7 & 10002.6 & 11308.2 & 9540.7 & 9942.4 \\
\hline
\end{tabular}

*In US Dollars. "Based on a stochastic model using the cost estimation module in @Risk. ${ }^{* *}$ On a base of 100 cows treated per protocol. ${ }^{* * *}$ This does not include the days before treatment. ${ }^{* * * *}$ This is the sum of the cost due to days open + the extra cost due to AI straws used, assuming a cost of \$10.00 US Dollars per straw.

\subsection{Estimated Economic Losses Associated to Reproductive Failure per Protocol}

The failure of getting the cows pregnant at first service adds to the costs for days open and additional AI straws used until the pregnancy of the cows in a hypothetical fourth service. Protocol A was the best cost-effective because its additional costs were the lowest among all protocols and had the lowest amount of open days (2107.7 to $2231.7 \mathrm{~d}$ ) and IA straws (average $=134$ ), then, the additional costs reached almost $\$ 6940.00$ on average. Protocols B and D were less efficient, with more than $3200 \mathrm{~d}$ of additional open days due to reproductive failure, reaching, on average, more than $\$ 10500.00$ in additional costs after four simulated rounds of AI keeping constant the pregnancy rate observed in each protocol. On the other hand, the protocols $\mathrm{C}$ and $\mathrm{E}$ occupied an intermediate position; however, both had estimated additional costs over $\$ 9300.00$ (Table 3). The sensitivity analysis indicated that the most important source of variation in the model assessing the economic losses was the pregnancy rate of the protocols.

\section{Discussion}

The use of pharmacological agents to promote estrous expression is a technique to ascertain a massive use of Artificial Insemination in cattle raised under tropical conditions. The value of this procedure has to be meas- ured by the number of animals pregnant after an intervention. It is however, a rather difficult task to compare fertility results between different experiments for the variability that exists in each field trial. The protocols tested in the present study afforded an overall fertility of $52 \%$ which is rather similar to many of the studies reviewed; in effect, conception rates after treatment with hormonal combinations in different studies vary between $40 \%$ and $70 \%$ [12-17]. Reviews of several studies have been published by Bo et al. [5] and Barusselli et al. [18] and earlier by Galina and Arthur [19]. The ranking of all these studies established an average of around 40\% ranging from $20 \%$ to $60 \%$ after first insemination. Nonetheless, the remaining non-pregnant animals had the inherent cost of being inseminated, especially if fixed time insemination is used, with negative results resulting in lengthier periods of days open. Most of the studies report the number of animals pregnant following an intervention but hardly any information if the non-pregnant animals were actually at the risk of becoming pregnant. Diaz et al. [20] in a survey where cows were sampled for progesterone following a protocol of synchronization observed that $30 \%$ of the animals did not form a CL. Moreover, in an old study Landivar et al. [21] compared fertility in different herds, either following spontaneous or synchronized estrus and using either natural mating or artificial insemination, reported no differences in fertility if AI or natural mating were used being the variation the 
animals utilized in the study rather than the technique to make them pregnant. So, the relationship of cost-benefit of synchronizing zebu cows with the goal of pregnancy should be an exercise that practitioners should undertake before embarking in costly protocols which are not costeffective. Two of the main challenges of zebu cattle under tropical conditions are the long postpartum anestrus and the low estrus detection rate [5,19]; so the protocols for synchronization of ovulation can have large positive impacts on the reproductive efficiency in the herds raised under tropical conditions if adequately used [6].

Several protocols have been tested for estrus synchronization, since the early days of utilizing only prostaglandins, to those more elaborate using progestins, estrogens and GnRH [12,13,17,22-25]. Diverse studies have documented the success of several protocols applied in diverse climatic conditions, different breeds, time postpartum where the intervention was undertaken and feeding strategies. However, studies comparing the results of protocols used on the same field conditions applied routinely by practitioners in different management conditions are less frequent. Besides, several progesterone or progestins have been investigated for estrus synchronization in zebu cows in controlled conditions, varying considerably the success in synchronization and gestation rates $[12,13,17,18,24]$.

Whilst rates of gestation of the protocols tested in the present report are similar to others, we are aware that the absence of the characteristics for each cow included in the study, did not allow us to carry out a mixed model including fixed and random effects, which could assess the effect of variables such as breed, number of parities, body condition score and time postpartum among others taking into consideration the random effect of the herd, on the synchronization and pregnancy rates. What we can assume is that there aren't differences between the body condition score, number of parities and time postpartum, as well as the breeds between protocols. In this scenario we can take for granted a global similarity of the groups treated. A favorable argument is that all cows of the study were selected by only two veterinarians who were the same that applied the treatments and undertook the pregnancy diagnosis hence the sources of error were equally distributed in all protocols.

Some studies report the costs of hormonal treatments for synchronization in beef cattle, most of them in Bos taurus; however, the calculations are based on the costs of hormonal treatment, without taking into consideration fixed cost such as labor and the possibility of applying various treatments in the case of cows having to be reinseminated. Also, fewer studies used mathematical models to simulate the effect of measures of management on the net income of a beef farm [26] the modeling of the cost-benefit of different protocols taking into account other aspects such as the cost of the IA straws, the added value of labor as well as the cost of the days open, are exercises that should be taken to understand the economic merit of hormonal treatments. Bolivar and Maldonado [27] and Alarcón et al. [28] have attempted to analyze the cost-benefit of using embryo transfer in cattle; their results indicate that the technique might be overvalued for the average farmer for it has its place in stud farming.

In conclusion, synchronization of estrus using pharmacological products seems to have a place in the management of cattle and its popularity has expanded in the last decade. However, caution should be called upon a careful assessment both from the part of the farm and the professional in charge of the enterprise to avoid using the technique indiscriminatively thus propitiating the use of a method that might not be cost-efficient.

\section{REFERENCES}

[1] P. I. Rekwot, E. O. Oyedipe, E. Mukasa-Mugerwa, V. O. Sekoni, O. P. Akinpelumi and A. A. Anyam, "Fertility in Zebu Cattle (Bos indicus) after Prostaglandin Administration and Artificial Insemination,” Veterinary Journal, Vol. 158, No. 1, 1999, pp. 53-58. doi:10.1053/tvjl.1998.0313

[2] M. G. Diskin and J. M. Sreenan, "Expression and Detection of Oestrus in Cattle," Reproduction and Nutrition Development, Vol. 40, No. 5, 2000, pp. 481-491. doi:10.1051/rnd:2000112

[3] C. S. Galina and A. Orihuela, "The Detection of the Estrus in Cattle Raised under Tropical Conditions: What We Know and What We Need to Know," Hormones and Behavior, Vol. 52, No. 1, 2007, pp. 32-38. doi:10.1016/j.yhbeh.2007.03.025

[4] A. Orihuela, "Some Factors Affecting the Behavioural Manifestation of Oestrus in Cattle: A Review," Applied Animal Behavior, Science, Vol. 70, No. 1, 2000, pp. 1-16. doi:10.1016/S0168-1591(00)00139-8

[5] G. A. Bo, P. S. Baruselli and M. F. Martínez, "Pattern and Manipulation of Follicular Development in Bos indicus Cattle," Animal Reproduction Science, Vol. 78, No. 3-4, 2003, pp. 307-326. doi:10.1016/S0378-4320(03)00097-6

[6] O. Gomes-de Sá Filho and J. L. Moraes-Vasconcelos, "Treatments to Optimize the Use of Artificial Insemination and Reproductive Efficiency in Beef Cattle under Tropical Environments," Veterinary Medicine International, Vol. 2011, No. 2011, 2011, Article ID 923053.

[7] G. A. Bo, L. Cutaia, L. C. Peres, D. Pincinato, D. Maraña and P. S. Baruselli, "Technologies for Fixed-Time Artificial Insemination and Their Influence on Reproductive Performance of Bos indicus Cattle," Society of Reproduction and Fertility Supplement, Vol. 64, 2007, pp. 223-236. http://www.ncbi.nlm.nih.gov/pubmed/17491150

[8] K. L. Macmillan, "Recent Advances in the Synchronization of Estrus and Ovulation in Dairy Cows," Journal of Reproduction Development, Vol. 56, 2010, pp. S42-S47.

[9] B. A. Tenhagen, M. Drillich, R. Surholt and W. Heuwieser, "Comparison of Timed AI after Synchronized Ovula- 
tion to AI at Estrus: Reproductive and Economic Considerations," Journal of Dairy Science, Vol. 87, No. 1, 2004, pp. 85-94.

doi:10.3168/jds.S0022-0302(04)73145-8

[10] C. J. H. de Sousa and J. C. Ferrugem-Moraes, "Manual de Sincronização de Cios em Ovinos e Bovinos,” Embrapa Pecuária Sul, Rio Grande do Sul, Brasil, 1998.

[11] P. A. Oltenacu, J. D. Ferguson and A. J. Lednor, "Economic Evaluation of Pregnancy Diagnosis in Dairy Cattle: A Decision Analysis Approach," Journal of Dairy Science, Vol. 73, No. 10, 1990, pp. 2826-2831. doi:10.3168/jds.S0022-0302(90)78970-9

[12] J. R. Pursley, M. C. Wiltbank, J. S. Stevenson, J. S. Ottobre, H. A. Garverick and L. L. Anderson, "Pregnancy Rates per Artificial Insemination for Cows and Heifers Inseminated at a Synchronized Ovulation or Synchronized Estrus,” Journal of Dairy Science, Vol. 80, No. 2, 1997, pp. 295-300. doi:10.3168/jds.S0022-0302(97)75937-X

[13] U. Singh, N. K. Khurana and Inderjeet, "Plasma Progesterone Profiles and Fertility Status of Anestrus Zebu Cattle Treated with Norgestomet-Estradiol-eCG Regimen," Theriogenology, Vol. 50, No. 8, 1998, pp. 1191-1199. doi:10.1016/S0093-691X(98)00219-2

[14] R. Cortes, J. A. Orihuela and C. S. Galina, "Effect of Sexual Partners on the Oestrus Behaviour Response in Zebu Cattle (Bos indicus) Following Synchronisation with a Progestagen (Synchromate B)," Asian-Australasian Journal of Animal Science, Vol. 12, No. 4, 1999, pp. 515-519.

[15] M. C. Cordoba and P. M. Fricke, "Evaluation of Two Hormonal Protocols for Synchronization of Ovulation and Timed Artificial Insemination in Dairy Cows Managed in Grazing-Based Dairies," Journal of Dairy Science, Vol. 84, No. 12, 2001, pp. 2700-2708. doi:10.3168/jds.S0022-0302(01)74724-8

[16] M. G. Maquivar, C. S. Galina, J. R. Galindo, S. Estrada, R. Molina and G. D. Mendoza, "Effect of Protein Supplementation on Reproductive and Productive Performance in Bos indicus $\times$ Bos taurus Heifers Raised in the Humid Tropics of Costa Rica,” Tropical Animal Health and Production, Vol. 42, No. 4, 2010, pp. 555-560. doi:10.1007/s11250-009-9470-0

[17] S. A. Buttler, P. C. Atkinson, G. B. Boe-Hansen, B. M. Burns, K. Dawson, G. A. Bo and M. R. McGowan, "Pregnancy Rates after Fixed-Time Artificial Insemination of Brahman Heifers Treated to Synchronize Ovulation with Low-Dose Intravaginal Progesterone Releasing Devices, with or without eCG," Theriogenology, Vol. 76, No. 8, 2011, pp. 1416-1423. doi:10.1016/j.theriogenology.2011.06.010

[18] P. S. Baruselli, E. L. Reis, M. O. Marques, L. F. Nasser and G. A. Bó, "The Use of Hormonal Treatments to Improve Reproductive Performance of Anestrous Beef Cattle in Tropical Climates," Animal Reproduction Science, Vol. 82, 2004, pp. 479-486.

\section{doi:10.1016/j.anireprosci.2004.04.025}

[19] C. S. Galina and G. H. Arthur, "Review of Cattle Reproduction in Tropics," Animal Breeding Abstracts, Vol. 59, No. 9, 1990, pp. 805-813.

[20] G. S. Díaz, C. S. Galina, C. H. Basurto and G. P. Ochoa, "Efecto de la Progesterona Natural con o sin la Adición de Benzoato de Estradiol Sobre la Presentación de Celo, Ovulación y Gestación en Animales Tipo Bos Indicus en el TrÓPico Mexicano,” Archivos de Medicina Veterinaria, Vol. 34, No. 2, 2002, pp. 235-244.

[21] C. Landivar, C. S. Galina, A. Duchateau and P. Navarro-Fierro, "Fertility Trial in Zebu Cattle after a Natural or Controlled Oestrus with Prostaglandin F2 $\alpha$ Comparing Natural Mating with Artificial Insemination," Theriogenology, Vol. 23, No. 3, 1985, pp. 421-429. doi:10.1016/0093-691X(85)90014-7

[22] G. A. Bo, G. P. Adams, R. A. Pierson, H. E. Tribulo, M. Caccia and R. J. Mapletoft, "Follicular Wave Dynamics after Estradiol-17B Treatment of Heifers with or without a Progestogen Implant,” Theriogenology, Vol. 41, No. 8, 1994, pp. 1555-1569. doi:10.1016/0093-691X(94)90821-Y

[23] J. E. Jefrisch and C. J. Ó Neill, “Calving Rates in a Tropical Beef Herd after Treatment with a Synthetic Progestagen, Norgestomet, or a Protaglandin Analogue, Cloprostenol,” Australian Veterinarian Journal, Vol. 73, No. 3, 1996, pp. 98-102.

[24] J. R. Baca, E. Pérez and C. S. Galina, “Comportamiento Reproductivo de Vacas Bos Taurus $\times$ Bos Indicus Bajo Programas de Inseminación Artificial a Estro Sincronizado y Natural en Condiciones del Trópico Seco de Costa Rica,” Veterinaria México, Vol. 29, No. 1, 1998, pp. 6773.

[25] J. N. Sales, J. B. Carvalho, G. A. Crepaldi, R. S. Cipriano, J. O. Jacomini, J. R. Maio, J. C. Souza, G. P. Nogueira and P. S. Baruselli, "Effects of Two Estradiol Esters (Benzoate and Cyprionate) on the Induction of Synchronized Ovulations in Bos indicus Cows Submitted to a Timed Artificial Insemination Protocol,” Theriogenology, Vol. 78, No. 3, 2012, pp. 510-516. doi:10.1016/j.theriogenology.2012.02.031

[26] L. A. Werth, S. M. Azzam, M. K. Nielsen and J. E. Kinder, "Use of a Simulation Model to Evaluate the Influence of Reproductive Performance and Management Decisions on Net Income in Beef Production,” Journal of Animal Science, Vol. 69, No. 12, 1991, pp. 4710-4721.

[27] P. A. Bolivar and J. G. Maldonado, “Análisis de Costos de Esquemas de Trasnferencia de Embriones Bovinos Utilizados en Colombia," Revista Colombiana de Ciencias Pecuarias, Vol. 21, No. 3, 2008, pp. 351-364.

[28] M. A. Alarcón, C. S. Galina, M. D. Corro and M. A. Asprón, "Embryo Transfer, a Useful Technique to Be Applied in Small Community Farms?” Tropical Animal Health and Production, Vol. 42, No. 6, 2010, pp. 11351141. doi:10.1007/s11250-010-9536-Z 